\title{
Documentos Pontificios en el Liber Testamentorum Ecclesie Ovetensis
}

\author{
$M^{a}$ JOSEFA SANZ FUENTES
}

En el primer tercio del siglo XII, en un momento clave para la supervivencia de la diócesis de Oviedo, ante la amenaza de las sedes de Compostela y Toledo que comenzaban a destacar entre todas las demás, desde la catedral ovetense e impulsado por Pelayo, arcediano primero de la misma, posteriormente auxiliar del obispo Martín I, a quien sustituye durante sus ausencias de la diócesis, y finalmente obispo titular, se procede a redactar y ejecutar la confección de uno de los cartularios más singulares no solo de la historia de la Diplomática hispana sino también de todo el occidente coetáneo: el «Liber Testamentorum Ecclesie Ovetensis», conocido también, a lo largo de la Edad Media como «Libro Gótico».

Creado para ser presentado ante el sumo pontífice con el fin de evitar que la diócesis fuese convertida en sufragánea de una de las recientes archidiócesis, concretamente de la de Toledo, y así poder seguir manteniendo su estatus de diócesis exenta, sometida directamente a la autoridad pontificia, el cartulario se plantea, tal y como lo describe en el siglo XVI el humanista Ambrosio de Morales, cuando, enviado por Felipe II, visita la catedral ovetense, y de manera más especial su riquísima biblioteca, como un libro en el cual se copiaron los documentos de los reyes y de los pontífices por los que se dotaba y consolidaba la diócesis ovetense. ${ }^{1}$

Su singularidad proviene del modo en el que ha sido ejecutado, con una solemnidad desmesurada, al crearse para su escrituración una caligrafia pseudocancilleresca, imitativa en parte de la escritura visigótica cursiva, propia de la época de los documentos en él copiados, e inventada para este caso muy probablemente por el propio $\mathrm{Pelayo}^{2}$, y sobre todo por la presencia de unas impresionantes miniaturas que, por una parte, en el caso de los documentos procedentes de la monarquía asturiana, dan entrada a todos y cada uno de los

1 Ambrosio de Morales: Viage de Ambrosio de Morales, por orden del rey don Phelipe II a los reynos de León y Galicia y Principado de Asturias. Para reconocer las Reliquias de Santos, Sepulcros Reales y Libros manuscritos de las Cathedrales y monasterios. Dale a la luz, con la vida del autor y con su retrato el Rev. P. Maestro fr. Henrique FlóreZ, Madrid 1765 (reimp. Oviedo 1977), pp. 93-98, esp. p. 95.

$2 \mathrm{M}^{\mathrm{a}}$ Josefa SANZ Fuentes: Estudio paleográfico, en: EADEM et al.: Liber Testamentorum Ecclesiae Ovetensis, Barcelona 1995, pp. 103-127. 
cuadernillos, dedicados de forma singular cada a uno de los monarcas de la misma, con una miniatura - tapiz, y que por otra intentan reflejar asimismo las características fisicas de los documentos en él copiados, que han sido en muchos casos sometidos a una refacción que los convierte en falsos diplomáticos pero que han sido acompañados por los signos de otorgantes y confirmantes de cada uno de ellos. ${ }^{3}$

En el caso que nos ocupa de forma especial, los documentos pontificios, son cuatro los copiados en el «Liber».

De los dos más cercanos al momento de redacción del mismo, los privilegios de Urbano II y de Pascual II, poco hay que decir, si no es la perfecta transcripción en el «Liber» de los originales que de los mismos se conservaban en el archivo catedralicio, así como también la minuciosa copia de los elementos figurados presentes en ellos, como son la rota y el bene valete. Ambos documentos resultan de excepcional importancia para la diócesis ya que por el primero de ellos Urbano II (1099, abril, 4. Letrán) confirma a la iglesia de Oviedo sus derechos y propiedades ${ }^{4}$, de ahí que tal vez como crítica a que solo se ocupara del poderío territorial de la diócesis sea representado en la miniatura que acompaña al documento tocado con un gorro propio de los señores territoriales y no de un papa, mientras que por el segundo Pascual II (1102, septiembre, 30, Civita Castellana) confirma a Pelayo, obispo de Oviedo, la libertad de no depender de ninguna otra diócesis metropolitana ${ }^{5}$. (fig. $1+2$ )

3 Joaquín YARZA LuACES: Las Miniaturas del Libro de los Testamentos, en: Liber Testamentorum, ed. de SANZ FUENTES et al. (como nota 2) pp. 145-230.

4 Santos A. García larragueta: Colección de documentos de la catedral de Oviedo, Oviedo 1962, p. 116, pp. 310-311.

5 García Larragueta (como nota 4) pp. 329-330. 


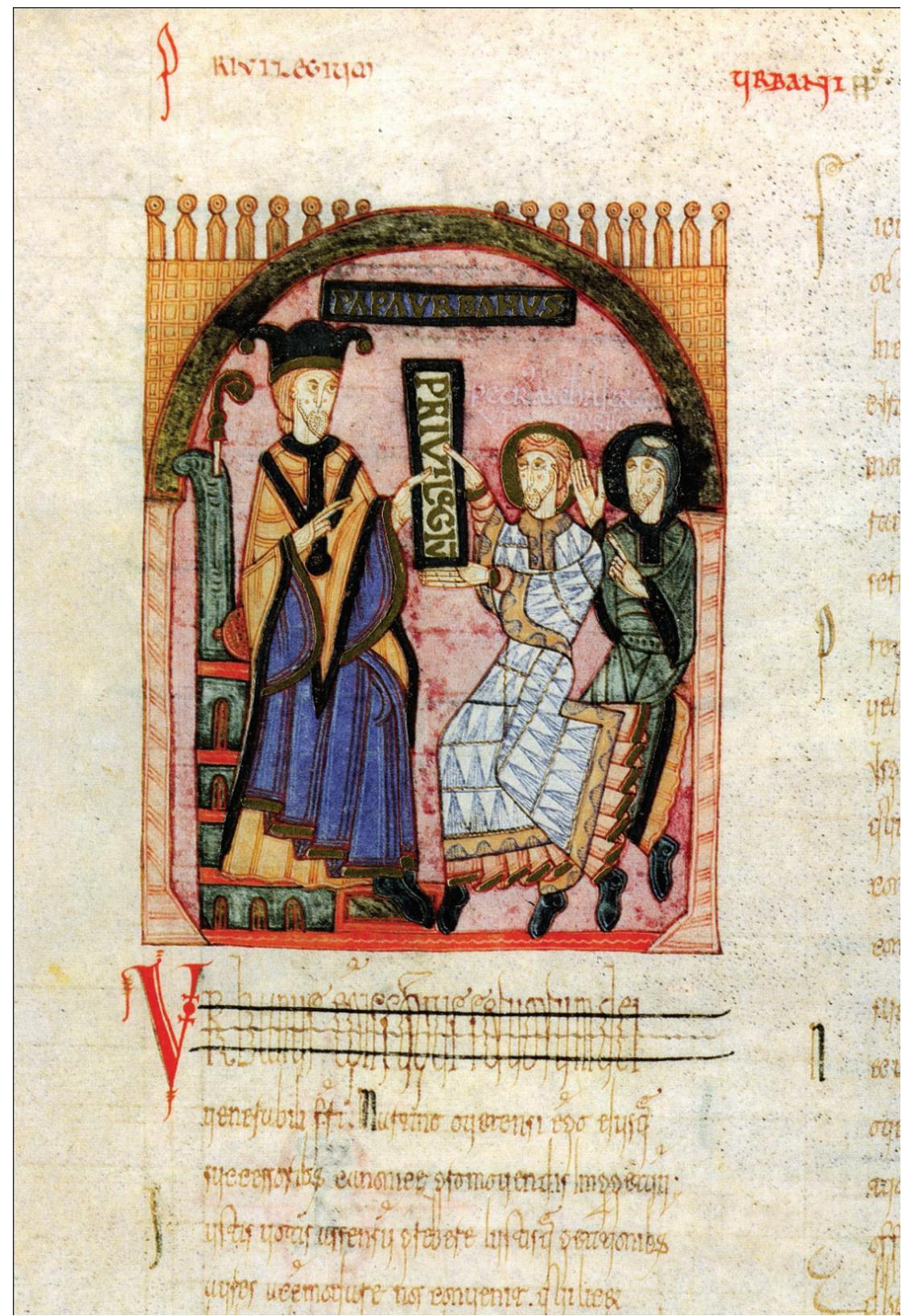

fig. 1 


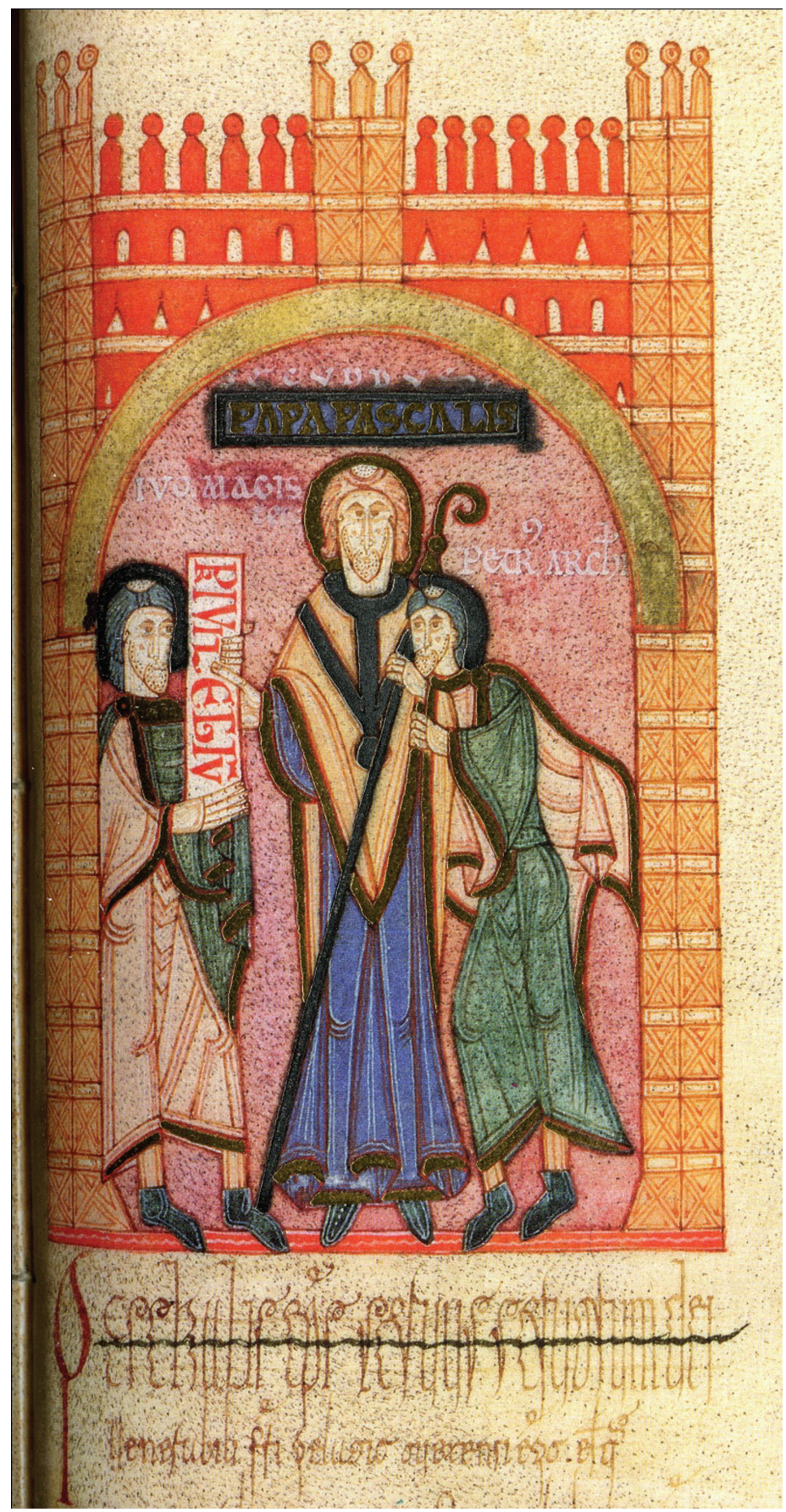

fig. 2 
Pero muchos más interrogantes han planteado y siguen planteando las dos denominadas epístolas enviadas por un papa Juan a un rey Alfonso cuyas cronologías no son posibles, si se pretende, como se hace en el cartulario, que ambas fueron dirigidas a Alfonso II el Casto en los años 821 y 822 respectivamente (fig. 3), siendo en cambio, en opinión de la mayoría de los autores que las han estudiado, factible que el pontífice y el rey en cuestión fueran Juan VIII (872882) y Alfonso III (866-910).

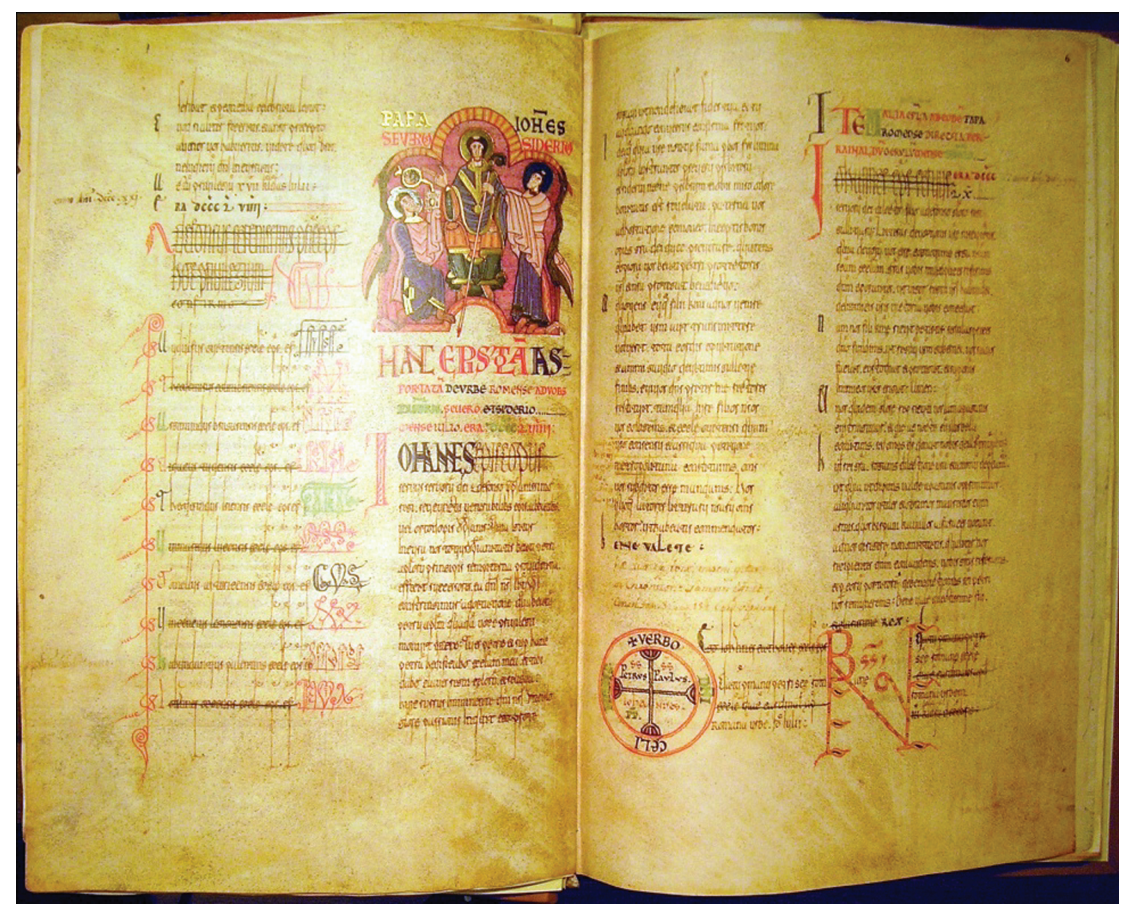

fig. 3

Estos dos documentos han sido ya objeto de numerosos estudios. Una primera aproximación a los mismos la realizó a principios de la década de los 60 del pasado siglo Floriano Cumbreño, señalando ya la inadmisibilidad de las dataciones propuestas y la presencia en unas sedicentes epístolas de los incongruentes elementos figurados de su validación propios de los privilegios más tardíos. ${ }^{6}$ En el mismo año, García Larragueta las edita también, y, aunque no les dedica un estudio pormenorizado, hace referencia en nota a pie de página a su incorrecta datación, sugiriendo fecharlas en el año 876, al haber encontrado documentos similares con esta data en los „Regesta Pontificum“ Jaffé e Ewald.

6 Antonio Floriano Cumbreño: En torno a las bulas del Papa Juan VIII en la Catedral de Oviedo, en: Archivum 12 (1962) pp. 117-127.

7 García Larragueta (como nota 4) pp. 40-41 y p. 45. 
En 1971 Fernández Conde lleva a cabo el primer estudio monográfico sobre el «Liber Testamentorum» dedicándole también un apartado al estudio de ambas bulas y a su carácter de falsos. ${ }^{8}$ En 1995 se publica una edición facsímil del códice, y en dos de los estudios que la acompañan se hace referencia a ambas bulas analizando los elementos figurados de las mismas. ${ }^{9} \mathrm{Y}$ ya más recientemente vuelve a incidir sobre las mismas Deswarte en un breve estudio sobre el obispo Pelayo. ${ }^{10}$

Desde hace ya mucho tiempo los documentos contenidos en el «Liber Testamentorum» han sido calificados de falsos y el obispo Pelayo de falsario. Desde entonces hasta ahora la Diplomática como ciencia ha avanzado lo suficiente como para enfocar el estudio de los cartularios desde el punto de vista de la función para la que han sido hechos y desde el concepto que de documento auténtico se tenía en la época en la que fueron escritos.

No cabe duda alguna de que Pelayo manipuló las fórmulas de los documentos que incluyó en este cartulario: sustituyó las duras y escuetas fórmulas de los documentos salidos del entorno de la monarquía asturiana por otras más elaboradas y más acordes con el latín culto de su propia época ${ }^{11}$ y refundió en uno solo varios documentos de un mismo monarca. ${ }^{12} \mathrm{Al}$ fin y al cabo Pelayo no está haciendo otra cosa que lo que pudo ver durante su estancia en el monasterio de Sahagún, donde se rehizo gran parte de la documentación perdida tras su destrucción por Almanzor utilizando, como el hará después en el «Liber», una falsa escrituta visigótica cursiva de aspecto arcaico, y redactándolos en cambio con fórmulas propias de la cronología en la que se están efectuando las refacciones. ${ }^{13}$ Estamos entonces en este caso hablando no de una falsificación absoluta: hasta ahora no se ha podido demostrar con claridad la falsedad de unos contenidos que en los documentos de donaciones territoriales nunca fueron contestados por ningún otro propietario, sino tan solo hablar de una falsifi-

8 Francisco Javier Fernández CONDE: El Libro de los Testamentos de la Catedral de Oviedo, Roma 1971, pp. 127-128.

9 SANZ Fuentes et al. (como nota 2) vid. especialmente pp. 128-131 y pp. 221-222.

10 Thomas Deswarte: ¿Una nueva metrópoli en Oviedo? Dos falsas bulas del obispo Pelayo (1098/1101-1130), en: La imagen del obispo hispano en la Edad Media, ed. de Martín Aurell/Ángeles García de LA BORbOlla, Pamplona 2004, pp. 153-166.

11 A la manipulación de las fórmulas dedica parte de su trabajo ya citado FerNÁNDEZ CONDE (como nota 8) pp. 89-102.

12 Lo hace con los de su amigo y coetáneo Alfonso VI, lo cual nos lleva a concluir que tal hecho no era tenido por manipulación en el momento en el que se está redactando el manuscrito.

13 Luis Romera Iruela: Refacciones documentales a fines del S. XI: el caso de Sahagún, en: Actas del VIII Coloquio del Comité Internacional de Paleografia Latina, Madrid 1990, pp. 185-201. José Antonio FernáNDEZ Flórez/Marta HerRero DE LA FUENTE: Libertades de los copistas en la confección de cartularios: el caso del Becerro Gótico de Sahagún, en: Scribi e colofoni. Le sottoscrizioni di copisti dalle origini all'avvento della stampa, ed. de Emma CONDELlo/Giuseppe De GrEGORIO, Spoleto 1995, pp. 301-320. 
cación diplomática: sí se manipulan ampliamente las fórmulas de redacción de los documentos.

Pero en el caso de las bulas del papa Juan la falsificación es más importante ya que llega a afectar a su datación.

Clarísima es la manipulación formularia de ambos documentos al introducir los elementos de validación propios de los privilegios pontificios, inexistentes en la época en la que aparecen datadas e incluso en la época más tardía, en la que parece que efectivamente fueron emitidas. Para ello Pelayo se vale de la documentación existente en el archivo de la catedral ovetense, archivo que conocía en profundidad, porque entre otras cosas es muy probable que antes de alcanzar la dignidad episcopal hubiera sido notario del mismo, lo que le permitió adquirir la información que luego utilizó en gran parte en sus obras historiográficas ${ }^{14}$ para dotarlas de tales elementos de solemnidad.

Muy probablemente no hizo falta en absoluto una estancia en Roma del obispo Pelayo, como expone Deswarte ${ }^{15}$, para que pudiera conocer los usos de la cancillería pontificia. Lo único que hace es aplicar a la refacción de unos documentos antiguos lo más moderno que tiene delante de su vista, que son ni más ni menos que los elementos existentes en el privilegio de Pascual II, hecho que resulta aún mucho más convincente si tenemos en cuenta que ese privilegio de Pascual II es precisamente el que reconoce de una manera definitiva que la diócesis ovetense es y seguirá siendo diócesis exenta. Así convierte un posible privilegio original en papiro del papa Juan en algo mucho más comprensible a la vista de sus coetáneos, que no entenderían un privilegio pontificio sin rota, utilizada en los privilegios a partir del $\mathrm{S}$. XI ${ }^{16}$, y benevalete. Más aún cuando incluso consigue hacer visible también el único elemento de validación que no se puede transmitir mediante la escritura. Y es que las bulas coetáneas ya llevaban un tercer elemento de validación característico. Por ello Pelayo introduce en la miniatura que encabeza la trascripción de ambos documentos, en la que se representa al papa Juan y a los dos eclesiásticos que portaron la primera de ellas hasta Oviedo, identificados por sus nombres, Siderio y Severo (fig. 4), ese elemento: el sello.

Del documento que Juan entrega a Severo y que es calificado en la misma miniatura como privilegio, pende un sello. El miniaturista dibujó con todo esmero el tipo del sello, que no es otro que la representación iconográfica de San Pedro recibiendo de manos de Dios las llaves (fig. 5), tipo que, introducido por Víctor II, será utilizado a lo largo de la segunda mitad del siglo XI y que el

14 SANZ FUENTES et al. (como nota 2) pp. 140-141.

15 Deswarte (como nota 10) p. 160.

16 Paulius RabiKaUSKas: Diplomatica pontificia, $4^{a}$ ed., Roma 1980, p. 36. La rota más antigua conocida corresponde al pontificado de León IX y se data el año 1051 (Giulio Battelli: Acta Pontificum, Città del Vaticano 1965, lám. 5). 
propio Pelayo pudo conocer de forma directa pendiente del privilegio de Urbano II. ${ }^{17}$

¿Cuál fue la base para la refacción de ambas bulas? Muy probablemente dos existentes de Juan VIII dirigidas a Alfonso III. Y Pelayo manipuló en este caso no solamente parte de sus fórmulas, ya identificadas por Floriano ${ }^{18}$ y Fernández Conde $^{19}$ y recogidas por Deswarte ${ }^{20}$, y los evidentes elementos de validación, sino que en este caso también manipuló la fecha.

Como anteriormente he indicado, ya existe un claro acuerdo en que las dos bulas originales sobre las que se basan las escritas en el «Liber» fueron expedidas en tiempos de Juan VIII y que su receptor no podía ser en absoluto Alfonso II, sino Alfonso III, coetáneo de este pontífice. Si tenemos en cuenta que es en el reinado de Alfonso III cuando se sitúa con certeza la transformación de la iglesia de San Salvador, fundada por Alfonso II, en iglesia catedral, cabecera por ello de diócesis ${ }^{21}$, sería también normal que para ello Alfonso III buscara la confirmación pontificia, con la que estaría relacionado el primero de los dos documentos, mientras que el segundo no sería ni más ni menos que la petición de una contrapartida por parte del pontífice, como es la ayuda de unos hombres acostumbrados a lidiar contra los sarracenos para defender a una Roma amenazada en aquellos momentos por el mismo peligro.

17 RABIKAUSKAS: Diplomatica (como nota 16) pp. 52-53 y Thomas FrenZ: I documenti pontifici nel medioevo e nell'età moderna, Città del Vaticano 1989, pp. 48-49.

18 Floriano Cumbreño (como nota 6).

19 FERNÁNDEZ CONDE (como nota 8) pp. 127-128.

20 Deswarte (como nota 10) pp. 156-157.

21 Miguel Calleja Puerta: La etapa fundacional del obispado de Oviedo, en: Maravillas de la España medieval. Tesoro sagrado y monarquía. I: Estudios y catálogo, León 2001, pp. 215-217. 


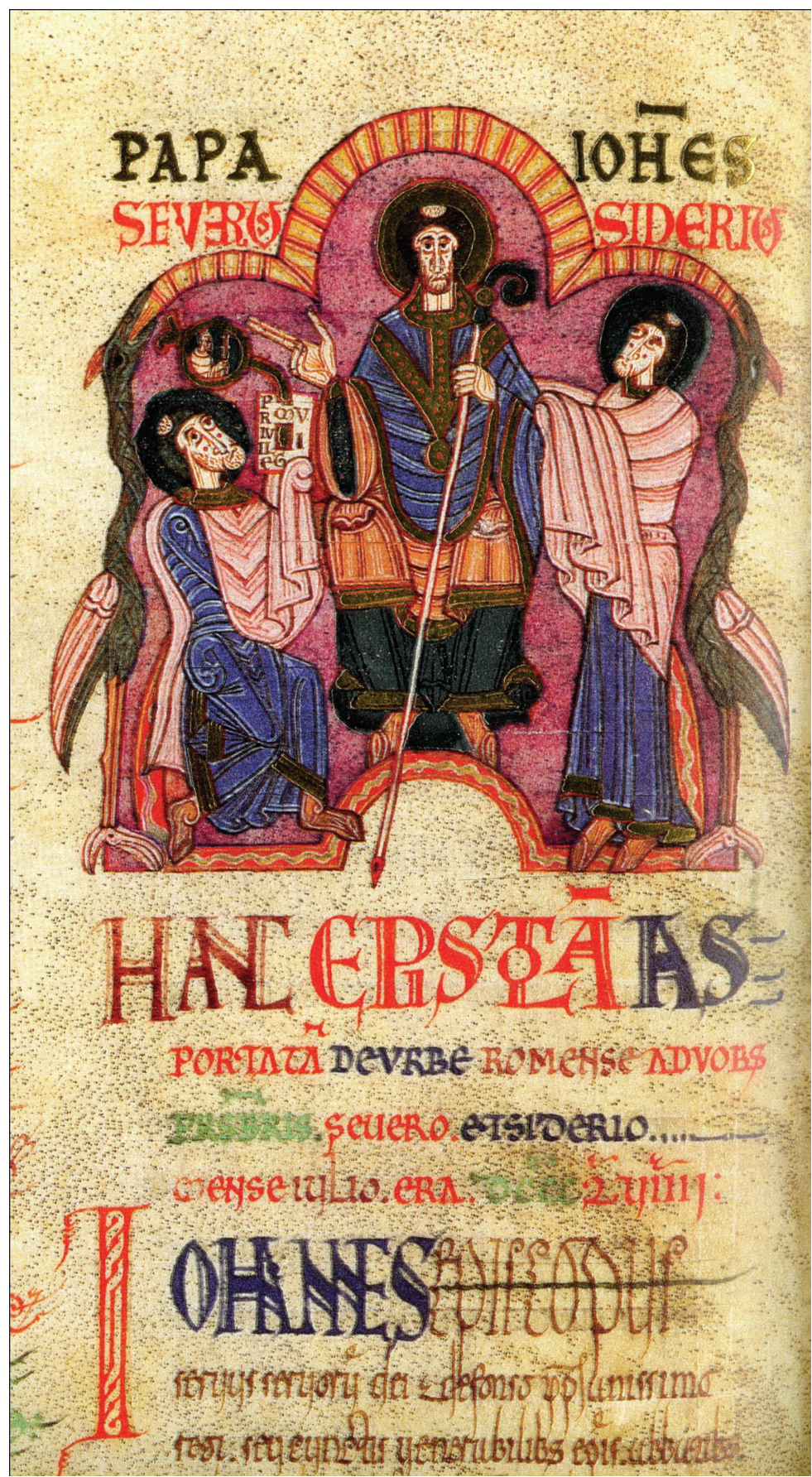

fig. 4 


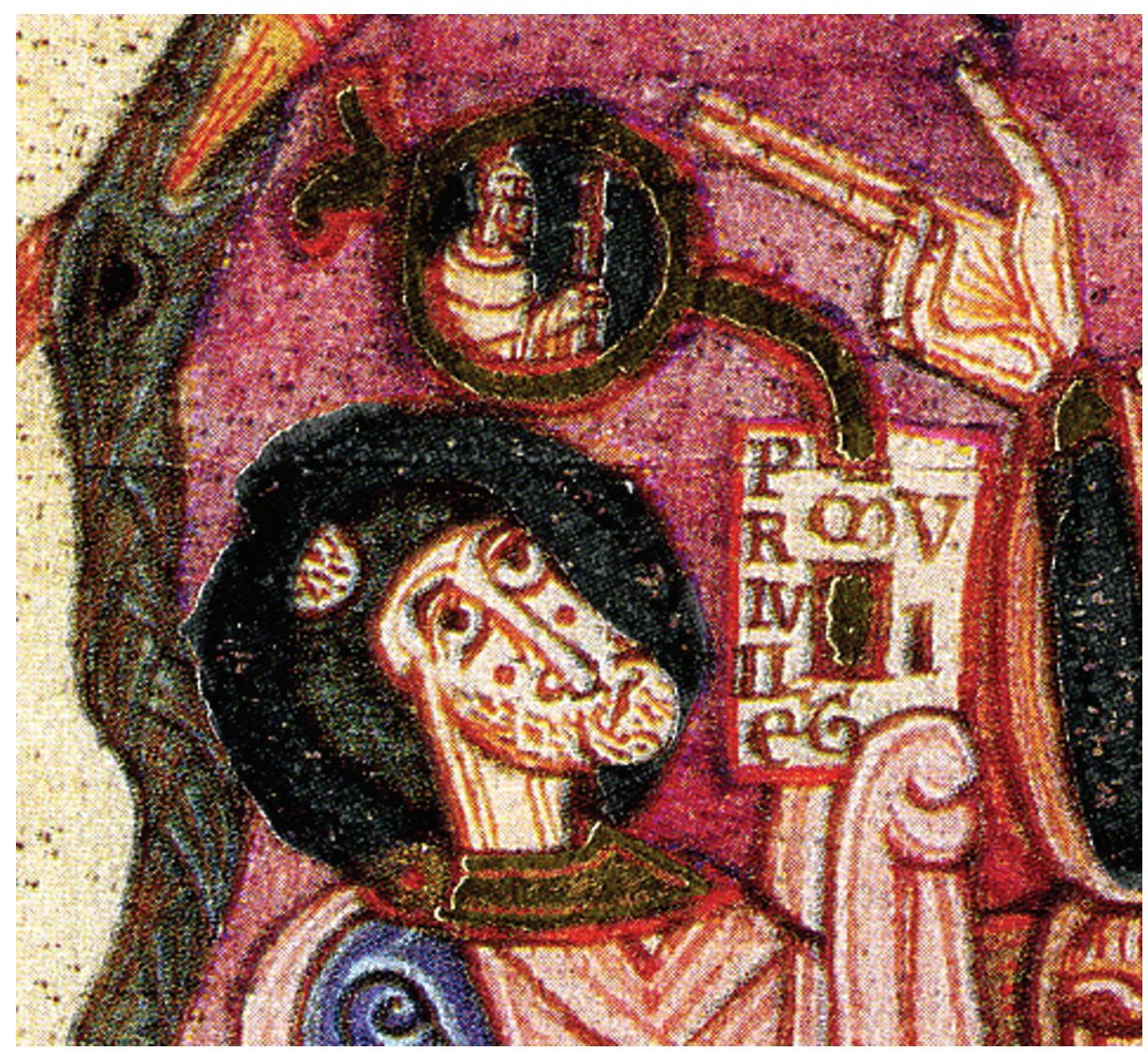

fig. 5

¿Por qué Pelayo traslada ambos documentos al reinado de Alfonso II? El «Liber Testamentorum» es mucho más que un simple cartulario, es decir que la copia en un solo volumen de los documentos que se hallaban en el tesoro de la catedral de Oviedo con el objeto de facilitar su manejo. Como bien dice Tock, la defensa de los privilegios de una institución religiosa no pasa solamente por una buena gestión de sus archivos, sino que requiere el desarrollo de una propaganda que afiance el prestigio de la institución. ${ }^{22} \mathrm{Y}$ durante el pontificado de

22 Benoît-Michel Tock: Les textes non diplomatiques dans les cartulaires de la province de Reims, en: Les cartulaires. Actes de la table ronde (Paris, décembre 1991), publ. par Olivier Guyotjeannin/Laurent Morelle/Michel Parisse, Paris 1993, p. 53. 
Martín I y de Pelayo la fortaleza de la diócesis ovetense es puesta a prueba: Oviedo debe de ser defendida no sólo de ser declarada sufragánea de la emergente archidiócesis toledana sino que las diócesis de Lugo, Orense y Burgos comienzan a reclamar para sí tierras que hasta estos momentos habían pertenecido a San Salvador de Oviedo. ${ }^{23}$ Por ello no es de extrañar que Pelayo quiera llevar el origen de la diócesis ovetense y su exención a los tiempos de Alfonso II, monarca muy conocido en aquellas fechas en las que la apertura del Arca Santa en el año 1075 había lanzado a toda Europa la noticia de que era este monarca quien la había hecho llegar hasta Oviedo desde el Monsacro y quien había construido un edificio para alojarla; y adorando el arca santa aparece representado en la miniatura que abre el «Liber Testamentorum» (fig.6).

Fue la defensa de los intereses de su diócesis la que le llevó a manipular las fechas de los documentos. No son por ello falsos absolutos. Es mucho más que probable que en el momento en que los rehizo tuviera ante sí los originales de Juan VIII, y el hecho de no poder cuadrar cronológicamente a Juan VIII con Alfonso II es lo que le impulsa a no incluir dentro de la rota con la que completa su refacción, copiada hasta en el más mínimo detalle de la que ornaba el privilegio de Pascual II, el numeral correspondiente al papa (fig. 7).

Son pues las epístolas del papa Juan dos más de las refacciones pelagianas hechas con el único objetivo de defender el prestigio de la diócesis ovetense.

23 SANZ FUENTES et al. (como nota 2). 


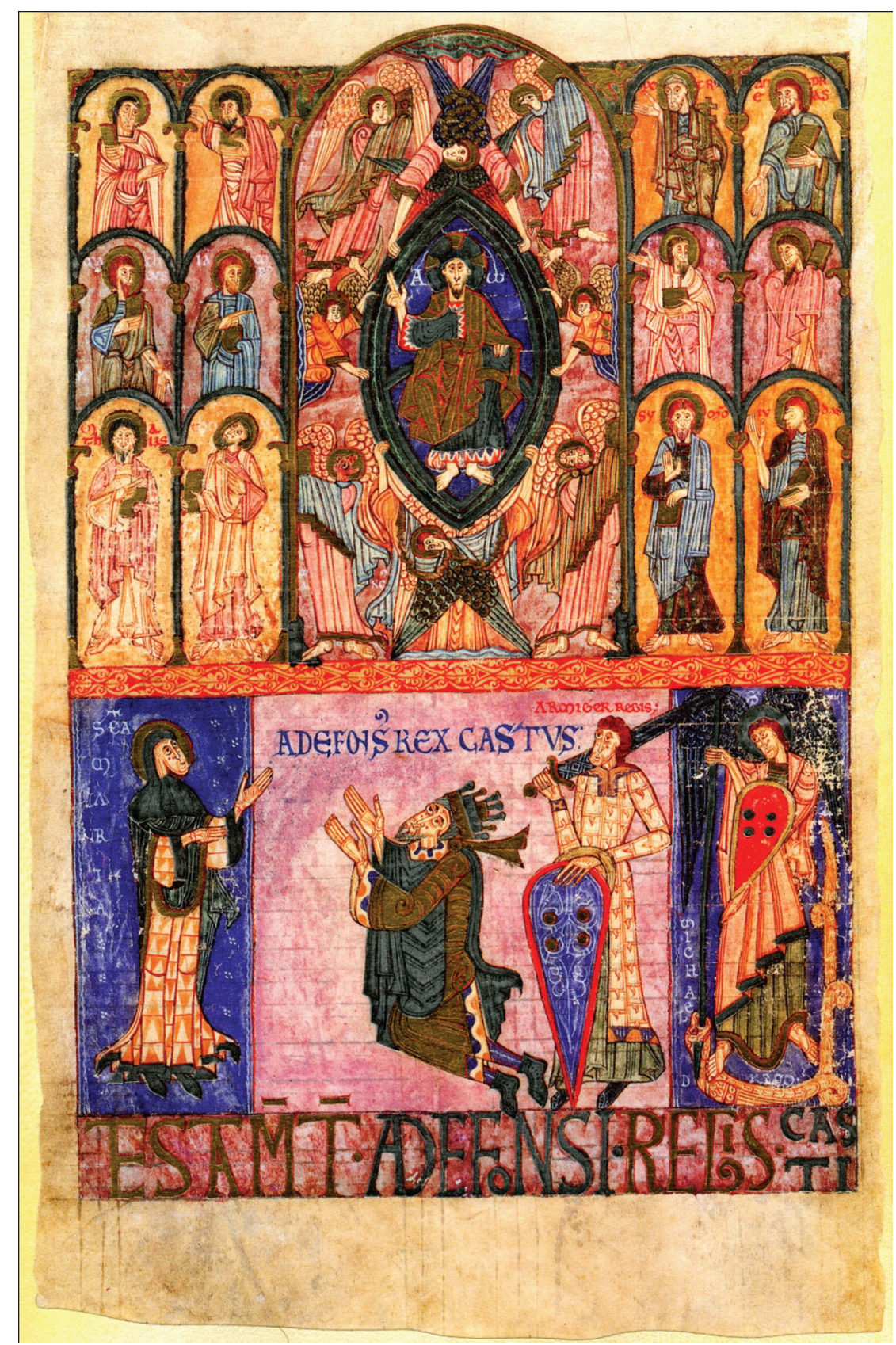

fig. 6 


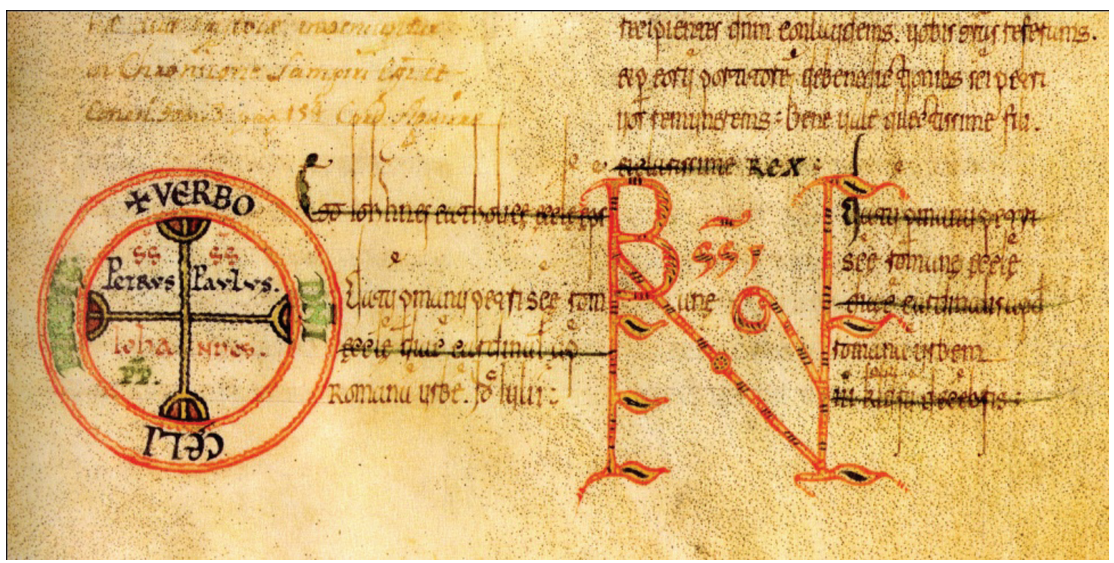

fig. $7 \mathrm{a}$

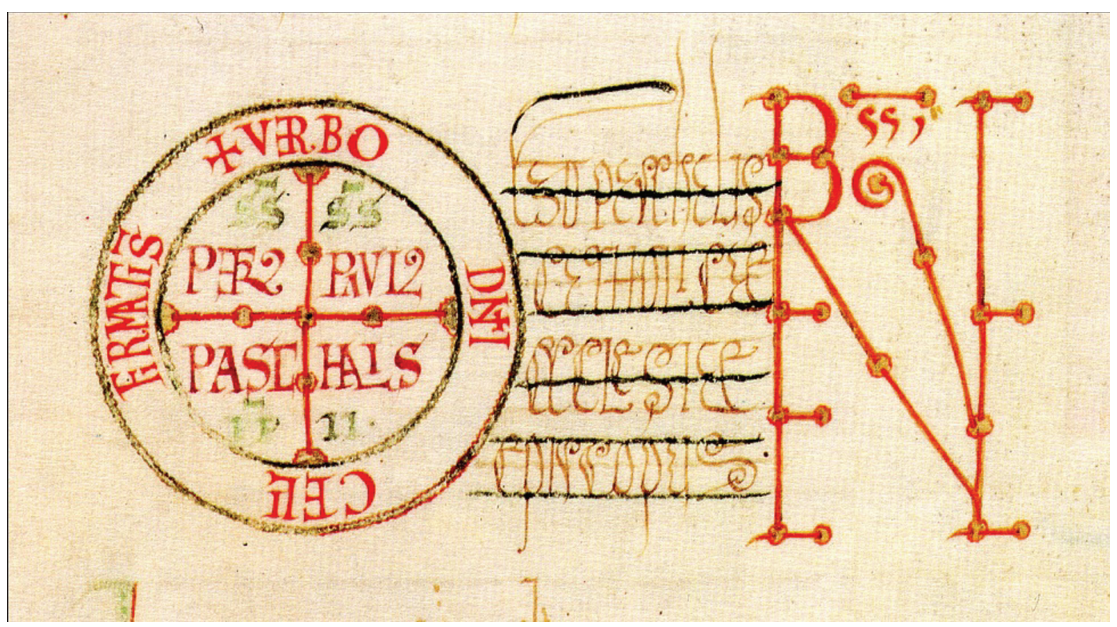

fig. $7 b$ 


\begin{abstract}
Papal Documents in the Liber Testamentorum Ecclesie Ovetensis

Diplomatic criticism applied to four pontifical documents copied in the cartulary Liber Testamentorum Ecclesiae Ovetensis. The analysis deals specially with the forgery of the so-called corpus Pelagianum established in the beginning of the twelfth century and focuses on the two oldest documents (Pope John VIII) and its reflect in the illumination of the book.
\end{abstract}

